\title{
REVITALISASI DAN PENGEMBANGAN KERAJINAN TENUN $A G A L$ DI DESA BUNGA MEKAR NUSA PENIDA KLUNGKUNG BALI
}

\author{
N.L.R. Purnawan ${ }^{1}$, A.A.R. Remawa ${ }^{2}$, IG. Suranjaya ${ }^{3}$, I.M. Radiawan ${ }^{4}$
}

\begin{abstract}
ABSTRAK
Pengembangan pariwista di Desa Bunga Mekar Nusa Penida perlu dibarengi dengan pengembangan produk yang dapat berfungsi sebagai kenangan (souvenir) yang harus dapat disediakan masyarakat sebagai salah satu daya tarik dan secara ekonomi dapat meningkatkan sumber penghasilan masyarakatnya. Produk kerajinan yang sangat unik dari Desa Bunga Mekar adalah kerajinan tenun Agal. Akan tetapi kondisi kerajinan tersebut pada saat ini telah hampir punah dan belum ada masyarakat ataupun desainer yang mengembangkannya. Tujuan dari pengabdian Masyarakat ini adalah untuk merevitalisasi dan mengembangkan tenun Agal khas Bunga Mekar Nusa Penida, sebagai usaha pelestarian peninggalan tenun tradisional yang pernah berkembang dan sekaligus sebagai sumber pendapatan bagi masyarakat di Nusa Penida. Pengabdian dilaksanakan selama 6 bulan, yang didahului oleh peninjauan lapangan, ceramah, pelatihan dan workshop. Hasil kegiatan menunjukkan bahwa pengabdian sudah berjalan dengan baik dicirikan oleh telah dicapainya beberapa target luaran yang telah ditentukan seperti tingkat kehadiran dan keseriusan peserta/mitra pengrajin tenun sangat tinggi, para pengrajin sudah mampu dan trampil mengoperasionalkan alat tenun bukan mesin (ATBM), serta telah terciptanya produk kain Agal dengan motif dan desain inovatif yang cocok dijadikan souvenir bagi wisatawan
\end{abstract}

Kata kunci : revitalisasi, pengembangan, kerajinan, kain tenun agal, souvenir

\begin{abstract}
The development of tourism in Desa Bunga Mekar Nusa Penida needs to be accompanied by the development of products that can function as memories (souvenirs) that must be provided by the community as an attraction and economically can increase the source of income of the community. A very unique handicraft product from Desa Bunga Mekar is the Aga weaving craft. However, the condition of the craft is now almost extinct and there is no community or designer who developed it. The purpose of this community service is to revitalize and develop Agal weaving typical of Nusa Penida's Bunga Mekar, as a preservation effort for the traditional weaving that has ever developed and at the same time as a source of income for people in Nusa Penida. The service was carried out for 6 months, which was preceded by field reviews, lectures, training and workshops. The results of the activities show that the service has been running well characterized by the achievement of a number of predetermined output targets such as the level of attendance and seriousness of the participants / partners of weaving craftsmen, the craftsmen are able and skilled to operate non-machine looms (ATBM), and the creation of looms Agal fabric products with innovative motifs and designs suitable as souvenirs for tourists
\end{abstract}

Keywords: revitalization, development, handicraft, Agal woven fabric, souvenirs

\footnotetext{
${ }^{1}$ Fakultas Ilmu Sosial dan Ilmu Politik, Universitas Udayana., ramaswati.purnawan@unud.ac.id

${ }^{2}$ Fakultas Seni Rupa dan Desain Institut Seni Indonesia Denpasar, remava@ISI.ac.id

${ }^{3}$ Fakultas Peternalan Universitas Udayana, gsuranjaya@unud.ac.id

${ }^{4}$ Fakultas Seni Rupa dan Desain Institut Seni Indonesia Denpasar radiawan@ISI.ac.id
} 


\section{PENDAhUluan}

Desa Bunga Mekar merupakan salah satu desa yang berada di wilayah Kecamatan Nusa Penida, Kabupaten Klungkung, Provinsi Bali. Desa Bungamekar terdiri atas tujuh dusun yaitu Dusun Pundukaha Kelod, Dusun Pundukaha Kaja, Dusun Sebuluh Kawan, Dusun Sebuluh Batugaing, Dusun Sompang, Dusun Karang Dawa, dan Dusun Punangkidan. Luas wilayah desa Bungamekar 19,730 km2 (1.973 Ha). Penduduk Desa Bunga Mekar sampai dengan tahun 2015 sebanyak 2.698 jiwa terdiri dari 1.302 laki-laki dan 1.396 perempuan.

Secara geografis Desa Bungamekar di sebelah utara adalah Desa Sakti dan Desa Klumpu, sebelah timur adalah Desa Batumadeg, sebelah selatan adalah Samudera Indonesia, dan sebelah barat adalah Desa Sakti. Topografi Desa bukit berobak hingga gelombang dengan struktur tanah bukit yang berbatu dan beriklim tropis dengan suhu kisaran $28 \mathrm{C}-32 \mathrm{C}$.

Desa Bunga Mekar memiliki banyak objek wisata yang terletak di bagian Selatan Pulau Nusa Penida dengan latar belakang pemandangan Samudra Indonesia. Semua objek wisata ini berada di tepi pantai yang terdiri dari 5 objek wisata yang berderet dari Barat ke Timur melalui 3 dusun yaitu: Pantai Pasih Uug, Pantai Pasih Andus, dan Pantai Bidadari Nusa Penida atau Angel Billabong sebutan yang diberikan oleh wisatawan mancanegara terletak di Dusun Sompang. Pantai Klingking dan Pura Paluang (car temple) terletak di Dusun Karang Dawa. Air Terjun Seganing yang terletak di Dusun Sebuluh. Objek wisata lainnya adalah objek wisata Pantai Lumangan yang masuk wilayah Banjar Dinas Penangkidan mempunyai daya tarik wisata yang sangat baik. Disekitarnya ada lokasi menyelam atau yang disebut Manta point. Banyak boat setiap hari yang datang membawa wisatawan kewilayah ini.

Pariwisata mulai berdenyut di Desa Bunga Mekar tahun 2015. Berkembanganya sektor pariwisata di lokasi itu, membuat banyak warga setempat beralih profesi. Masyarakat yang semula sebagaian besar hidup dari bertani dan beternak sapi, mulai beralih sebagai penjual jasa wisata. Masyarakat setempat mulai banyak yang membuat warung untuk wisatawan, rumah makan, dan ada juga yang membangun penginapan dan villa untuk menunjang akomodasi wisata. Namun demikian perkembangan pariwisata di Desa Bunga Mekar saat ini terbatas tertumpu pada keindahan alam saja, belum menggarap aspek budaya masyarakat yang sangat unik dan menarik bagi wisatawan. Pengembangan wisata diharapkan mampu memberikan manfaat yang optimal bagi masyarakat desa. Oleh sebab itu, pengembangan pariwisata diharapkan berbasis potensi desa, tidak saja daya tarik alam tetapi juga budaya, adat tradisi serta seni perlu dikemas menjadi daya Tarik wisata (Sardiana dan Purnawan, 2016). Begitu pula dengan pengelolaan daya Tarik agar sepenuhnya dilakukan oleh masyarakat local atau pariwisata berbasis kerakyatan (Sardiana dan Purnawan, 2015; Purnawan dan Sardiana, 2018).

Salah satu aktivitas/tradisi masyarakat yang menarik adalah kerajinan tenun kain agal. Kain agal adalah kain khas Desa Bunga Mekar yang sangat unik dan diyakini oleh masyarakat memiliki kekuatan magis. Keunikan kain ini terletak pada motif kain berupa garis-garis dan warna kain dari bahan alami. Kerajinan ini telah dilakukan secara turun temurun oleh masyarakat dan relative tidak mengalami perkembangan yang berarti. Begitu pula peralatan yang masih mempertahankan alatalat tradisional warisan leluhur. Sejalan dengan perkembangan jaman, jumlah pengrajin semakin berkurang dengan semakin terbatasnya pasar produk kerajinan ini. Perbaikan proses produksi dan manajemen serta inovasi desain produk sangat diperlukan untuk menggairahkan kembali industri tenun di Desa Tunas Mekar. Inovasi desain dimaksudkan adalah membuat desain produk menjadi produk yang lebih fasionable dan cocok dijadikan sebagai souvenir ikonik bagi destinasi wisata Nusa Penida. 
Pengabdian kepada masyarakat ini bertujuan untuk pengembangan kerajinan tenun kain agal khas Desa Bunga Mekar untuk menunjang pariwisata di Desa Bunga Mekar, Kecamatan Nusa Penida, Kabupaten Klungkung.

\section{METODE PELAKSANAAN}

Metode pengabdian masyarakat pada kegiatan ini adalah melalui pelatihan pembuatan desain, teknik menenun, dan rancang bangun alat tenun bukan mesin (ATBM). Dalam operasional kegiatan dilakukan melalui beberapa tahap, yaitu persiapan, pelaksanaan dan evaluasi. Pada tahap persiapan dilakukan perancangan alat tenun bukan mesin dan pengumpulan alat/bahan pengabdian seperti benang, lungsi, pakan dan lain-lain, melakukan sosialisasi dan kordinasi dengan kepala desa dan masyarakat calon peserta atau mitra kegiatan pengabdian masyarakat (kelompok pengrajin tenun), menyusun kesepakatan mengenai jadwal pelaksanaan kegiatan.

Tahap operasional meliputi kegiatan bimbingan teknis mengenai cara operasional ATBM, mengingat selama ini pengrajin menggunakan peralatan tenun tradisional, teknik menenun sesuai dengan desain yang sudah dibuat, dan teknik finising. Kegiatan bimtek dilanjutkan dengan pendampingan selama 6 bulan, yaitu melakukan suvervisi secara berkala setiap bulan sekali.

Tahap evaluasi dilakukan pada pertengahan dan akhir kegiatan melalui pengukuran terhadap beberapa indicator keberhasilan program yang telah ditetapkan. Evaluasi ini ditujukan untuk mengetahui sejauh mana kegiatan sudah mencapai hasil.

\section{HASIL DAN PEMBAHASAN}

Agal adalah tenun khas Desa Bunga Mekar Nusa Penida yang belum berkembang dan hampir punah. Beruntung masih ada masyarakat yang menyimpan jenis tenun Agal khas Bunga Mekar Nusa Penida bernama Bapak Wayan Tageg. Atas usahanya mengumpulkan dan melestarikan tenun Agal ini, informasi tentang Agal dapat diperoleh dan desainnya akan dapat dikembangkan untuk meragamkan tenun khas Bunga Mekar. Tenun ini memiliki motif geometris khususnya pada selendang dan motif garis pada kain sarungnya (kamben). Pada kain lembaran ini hanya menggunakan motif garis sederhana dengan warna biru tua, merah dan oranye.

Sebagai daerah tujuan wisata dan untuk meningkatkan ekonomi masyarakatnya sudah selayaknya Desa Bunga Mekar memiliki ciri khas barang kerajinan untuk mendukung objek wisata yang mulai terkenal tersebut. Salah satu yang dikembangkan dan dihidupkan kembali adalah tenun Agal yang diawali dengan survey lapangan, kemudian dilakukan ceramah dan pelatihan serta workshop selama dua bulan di Desa Bunga Mekar tersebut. Pelatihan yang digabungkan dengan pelatihan pembuatan sabun spa dan lulur khas Bunga Mekar diikuti oleh 17 orang dari ibu-ibu rumah tangga Desa Bunga Mekar. Namun karena keterbatasan dana maka pengabdian masyarakat ini hanya dapat membantu satu mesin ATBM (alat tenun bukan mesin) kepada satu orang perajin.
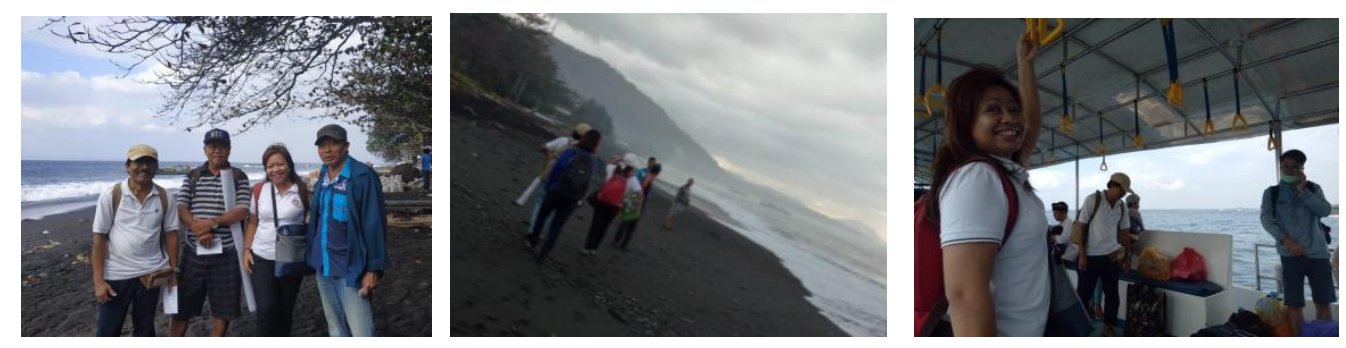

Gambar 1. Menuju Pelatihan ke Desa Bunga Mekar Nusa Penida 
Tahap awal (hari pertama) dilakukan pengiriman ATBM ke Desa Bunga Mekar melalui boat dan sekaligus merakit ATBM baru tersebut serta menyerahkannya kepada perbekel Desa Bunga Mekar. Pada hari kedua dilakukan ceramah tentang ATBM dan cara penggunaannya serta prospek desain tenun di masa depan. Di samping itu, hal penting lainnya adalah mengenal alat-alat ATBM dan bahan tenun seperti lungsi (gulungan benang dasar pada bum sebagai benang yang memanjang) dan pakan (benang dasar yang melintang sebagai motif). Berbagai bagian ATBM juga dikenalkan seperti tiang penyangga dan elemen lainnya; guun, bum, sisir, sekoci, pikes dan alat penunjangnya seperti jantra (alat penggulung benang pakan) yang sering dikenal dengan alat ngeling. Kemudian di hari ketiga dilakukan workshop yang diawali dengan pelatihan nglojeg, yaitu belajar mengayun sisir untuk melemaskan tangan dan kaki dalam menenun. Kegiatan ini dilakukan agar pada saat benang lungsi sudah dimasukkan ke guun dan sisir, keterampilan perajin dalam mengayun sisir dan menjalankan sekoci sudah baik. Selanjutnya diadakan pelatihan nyucuk (memasukkan benang lungsi pada guun dan sisir ATBM sehingga tenun bisa dioperasikan. Selama proses ini perajin didampingi instruktur lapangan yang bernama Bapak Gusti Made Karya dari Blahbatuh Gianyar agar segala permasalahan dapat diatasi secepat mungkin.
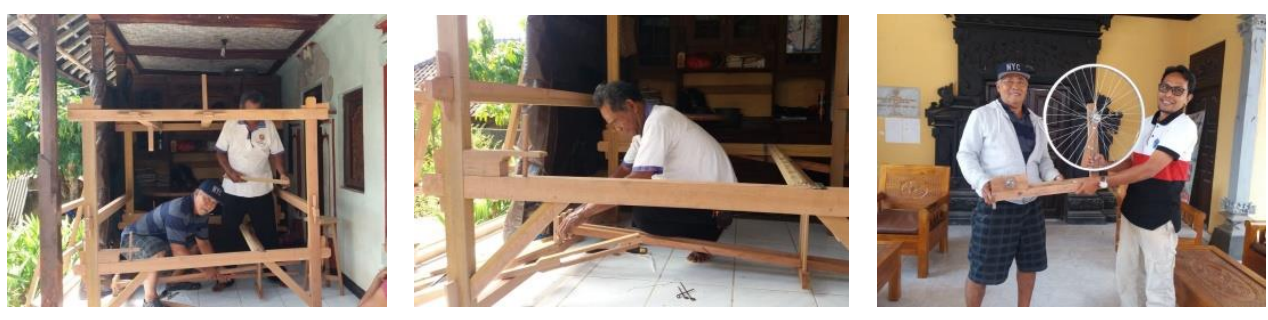

Gambar 2. Perakitan ATBM dan Penyerahan Alat Ke Perbekel Desa Bunga Mekar

Hari berikutnya setelah semua persiapan dan latihan keterampilan menggunakan ATBM dirasa cukup, baru kemudian dilakukan proses penenunan dengan motif sederhana. Pelaksanaan penenunan ini dilakukan selama berhari-hari sampai kain tenun dianggap baik untuk dilanjutkan dengan proses berikutnya yaitu pengembangan desain sebagai barang souvenir yang akan digunakan di Desa Bunga Mekar dan di beberapa objek wisata seperti Kelingking Beach. Berdasarkan hasil yang sudah dicapai oleh perajin dapat dijelaskan bahwa perajin memiliki kemampuan yang cukup baik untuk menenun, sehingga berbagai jenis kain dapat dihasilkan walaupun instruktur dan pengawas tidak berada di lapangan. Contoh hasil tenun karya perajin di Desa Bunga Mekar ini dapat dilihat pada model tenun dalam gambar berikut ini.
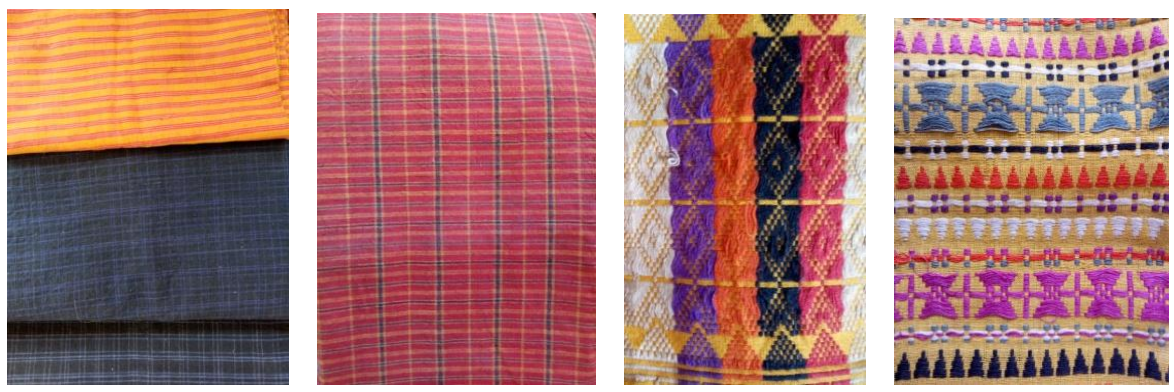

Gambar 3. Jenis dan Motif Agal yang masih ditemukan 

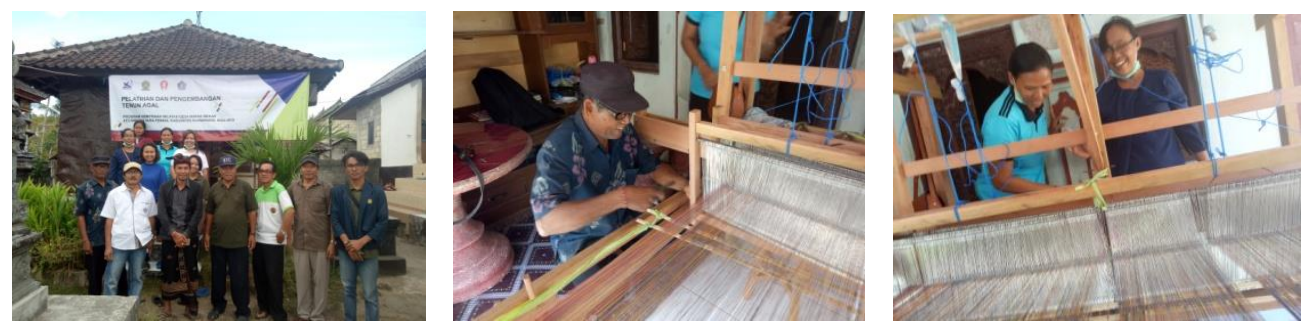

Gambar 4. Pelatihan Tenun Agal di Desa Bunga Mekar

Hasil dari diadakannya pelatihan ini adalah lembaran kain tenun yang siap dipasarkan, masih bermotif umum, dan belum dikembangkan ke dalam desain yang sesuai dengan tuntutan masa kini. Tahap selanjutnya akan diadakan pengembangan dengan motif untuk souvenir wisata Kelingking Beach yang desainnya sudah dirancang dan siap diberikan kepada perajin pada tahap pengabdian selanjutnya. Berbagai contoh hasil tenunan perajin yang telah dibuat dapat dilihat pada gambar berikut.
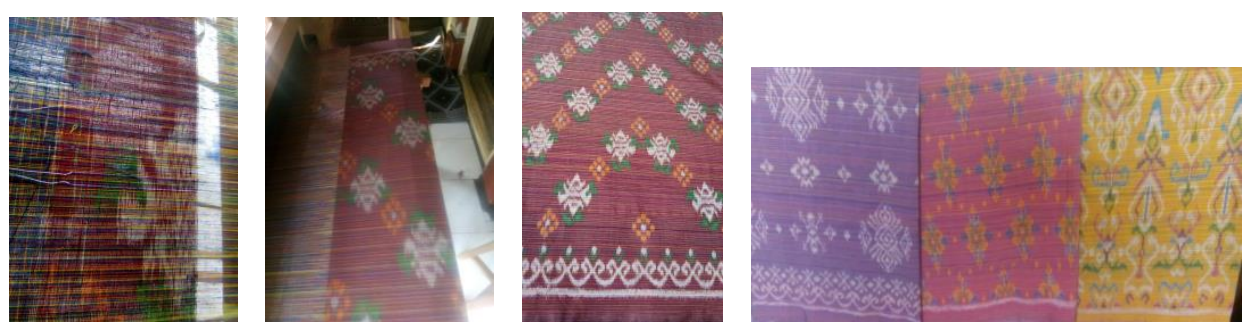

Gambar 5. Hasil Pelatihan Tahap Awal, dan Akhir Untuk Peningkatan Skill Menenun Di Desa Bunga Mekar Nusa Penida.

\section{KESIMPULAN}

Kegiatan pengabdian kepada masyarakat Revitalisasi dan pengembangan kerajinan tenun agal di Desa Bunga Mekar, Nusa Penida, Klungkung Bali sudah berjalan dengan baik dicirikan oleh telah dicapainya beberapa target luaran yang telah ditentukan seperti tingkat kehadiran dan keseriusan peserta/mitra pengrajin tenun sangat tinggi, para pengrajin sudah mampu dan trampil mengoperasionalkan alat tenun bukan mesin (ATBM), serta telah terciptanya produk kain Agal dengan motif dan desain inovatif yang cocok dijadikan souvenir bagi wisatawan.

\section{UCAPAN TERIMA KASIH}

Penulis mengucapkan terima kasih kepada Direktorat Riset dan Pengabdian kepada Masyarakat, Dirjen DIKTI melalui Lembaga Penelitian dan Pengabdian masyarakat Unud, dan Pemda Kabupaten Klungkung atas dana yang diberikan sehingga pengabdian masyarakat dapat dilaksanakan.

\section{DAFTAR PUSTAKA}

Anon. 2015. Profil Pembangunan Desa Antapan, Kecamatan Baturiti Kabupaten Tabanan.

[BPS] Badan Pusat Statistik. 2015. Kecamatan Nusa Penida dalam Angka tahun 2015. Badan Statistik Kabupaten Klungkung

Purnawan, NLR., I.K Sardiana. 2017. Paket Wisata Edukasi Subak Upaya Menjaga Keberlanjutan Potensi Pertanian dan Pariwisata Berbasis Budaya di Bali. Jurnal Kawistara 7 (3), 275-284 
Sardiana, IK. 2018. The Study of Development of Urban Farming Agrotourism Subak-Irrigation-Based in Sanur Tourism Area, Denpasar City, Bali. Journal of Indonesian Tourism and Development Studies 6 (1), 33-40

Sardiana, IK., NLR Purnawan., 2016. Indigenous community, ecotourism and sustainability: Experience from Tenganan Dauh Tukad traditional. Heritage, Culture and Society: Research agenda and best practices in the hospitality and tourism ind | vol: | issue : | 2016-01-01 | Conference Proceedin

Sardiana, IK., NLR Purnawan. 2015. Community-based Ecotourism in Tenganan Dauh Tukad: An Indigenous Conservation Perspective. Jurnal Kajian Bali (Journal of Bali Studies) 5 (2), 347-368 